\title{
PRÁTICA PEDAGÓGICA NA EDUCAÇÃO PROFISSIONAL DE NÍVEL MÉDIO EM ENFERMAGEM
}

\author{
Caroline Silva Morelato Coloni ${ }^{1}$, Verônica Modolo Teixeira ${ }^{2}$, Mirian Christine Olimpio Moreira ${ }^{1}$, Rafaela \\ Piotto $^{3}$, Fernanda dos Santos Nogueira de Góes ${ }^{4}$, Rosangela Andrade Aukar de Camargo ${ }^{5}$
}

\begin{abstract}
RESUMO: O presente estudo objetivou identificar as práticas pedagógicas desenvolvidas por professores da educação profissional de nível médio em enfermagem. Estudo descritivo qualitativo, cujo dados foram coletados por questionário semi-estruturados, entre outubro e novembro de 2013 em duas escolas profissionalizantes, com participação de 15 professores/enfermeiros. As frequências das respostas e conteúdo foram analisados à luz dos aspectos didático-pedagógicos da literatura. Dos entrevistados, $66,6 \%$ são mulheres, com formação pedagógica e experiência assistencial superior a 3 anos. O Projeto Pedagógico do Curso é desconhecido por 46,6\%; 53\% elaboram planos de aula; $86,6 \%$ afirmam realizar avaliação formativa, em contrapartida, a prova escrita é utilizada por $73,3 \%$. Com a conclusão do estudo, percebeu-se que em linhas gerais os professores desenvolvem uma prática educativa desprovida de reflexão e sentido ao não participar do planejamento do curso. Entretanto, a maioria faz planejamento da disciplina e da aula, ainda que utilize conceito equivocado sobre a avaliação da formação.
\end{abstract}

DESCRITORES: Educação em enfermagem; Educação profissionalizante; Ensino; Docentes.

\section{PEDAGOGICAL PRACTICE IN MID-LEVEL PROFESSIONAL NURSING EDUCATION}

\begin{abstract}
The aim of this study was to identify the pedagogical practices developed by professors of mid-level professional education in nursing. A qualitative descriptive study was conducted, with data collection through semi-structured questionnaires, between October and November 2013, in two schools, with the participation of 15 professors/nurses. The frequencies of the responses and content were analyzed in the light of didactic and pedagogical aspects of the literature. Of the respondents, $66.6 \%$ were women, with over three years of pedagogical education and healthcare experience. The pedagogical course project was unknown by $46.6 \%$; $53 \%$ claimed to elaborate lesson plans; $86.6 \%$ reported performing formative assessment; written tests, though, were only applied by $73.3 \%$. With the completion of the study, it was observed that professors generally develop an educational practice devoid of reflection and meaning when they do not participate in the course syllabus. The majority, however, plans the discipline, albeit using misconception on the evaluation of the training.
\end{abstract}

DESCRIPTORS: Nursing education; Professional education; Education; Faculty.

\section{PRÁCTICA PEDAGÓGICA EN LA EDUCACIÓN PROFESIONAL DE NIVEL MEDIO EN ENFERMERÍA}

RESUMEN: El estudio objetivó identificar las prácticas pedagógicas desarrolladas por profesores de educación profesional de nivel medio en enfermería. Estudio descriptivo, cualitativo; datos recolectados mediante cuestionario semiestructurado, entre octubre y noviembre de 2013 en dos escuelas profesionalizantes, participando 15 profesores/enfermeros. Las frecuencias de respuestas y contenido fueron analizadas de según los aspectos didáctico-pedagógicos de la literatura. De los entrevistados, $66,6 \%$ fueron mujeres con formación pedagógica y experiencia de atención superior a tres años. El Proyecto Pedagógico del Curso era desconocido por el 46,6\%; el 53,3\% elabora planes de clases; el 86,6\% refieren aplicar evaluación formativa. Como contrapartida, el 73,3\% aplica pruebas escritas. La conclusión del estudio percibe, en líneas generales, que los profesores desarrollan una práctica educativa desprovista de reflexión y sentido, al no participar de la planificación del curso. No obstante, la mayoría aplica planificación de materias y clases, aunque utilizando conceptualización equivocada sobre la evaluación de la formación.

DESCRIPTORES: Educación en Enfermería; Educación Profesional; Enseñanza; Docentes.

${ }^{1}$ Discente de Enfermagem. Universidade de São Paulo. Ribeirão Preto, SP, Brasil.

${ }^{2}$ Enfermeira. Enfermeira Autônoma. Ribeirão Preto, SP, Brasil.

${ }^{3}$ Enfermeira. Enfermeira Assistencial do Hospital do Câncer de Ribeirão Preto - Fundação Sobeccan. Ribeirão Preto - SP - Brasil. ${ }^{4}$ Enfermeira. Doutora em Enfermagem. Docente do Departamento de Enfermagem Geral de Especializada da Escola de Enfermagem de Ribeirão Preto da Universidade de São Paulo. Ribeirão Preto, SP, Brasil.

${ }^{5}$ Enfermeira e Pedagoga. Doutora em Enfermagem. Docente do Departamento de Enfermagem Materno-Infantil e Saúde Pública da Escola de Enfermagem de Ribeirão Preto da Universidade de São Paulo. Ribeirão Preto, SP, Brasil.

Universidade de São Paulo

R. J 340 - 14033-014 - Ribeirão Preto, SP, Brasil

E-mail: rcamarg@eerp.usp.br 


\section{- INTRODUÇÃO}

A prática pedagógica é um processo que está intrinsecamente ligado à articulação da teoria à prática da docência, que se constrói e se reconstrói no dia-a-dia, mediante exercício analítico cuidadoso para interpretá-la criticamente. Envolve múltiplas dimensões: a formação do professor, o perfil do aluno, a metodologia de ensino, os objetivos e conteúdos de aprendizagem, as estratégias de ensino, a avaliação educacional e a relação entre professor e aluno. Compreende-se que é determinada por aspectos conjunturais e estruturais da sociedade, imprescindíveis à consciência que se tem de educação, escola e da ação do professor ${ }^{(1-4)}$.

Como prática social, é guiada por objetivos, finalidades e conhecimentos. Neste sentido, o professor poderá desenvolver uma prática que seja transformadora, significativa e pertinente ao contexto social dos alunos ou poderá apropriar-se de uma prática mecânica, que tem como principal finalidade repassar conteúdos e realizar atividades meramente repetitivas ${ }^{(4-5)}$.

Nesta perspectiva, a prática docente na Educação Profissional de Nível Médio em Enfermagem responsável pela formação de técnicos de enfermagem passa por mudanças significativas, objetivadas nas Diretrizes Curriculares Nacionais (DCNs). Neste documento, encontram-se os princípios das práticas pedagógicas que norteiam o ato educativo, são eles: maior capacidade de raciocínio, autonomia intelectual, pensamento crítico, iniciativa própria, bem como capacidade de visualização e resolução de problemas do cotidiano ${ }^{(6)}$.

Sintonizado com estes princípios, o método ativo de aprendizagem, crítico e reflexivo passou a compor o ideário da legislação educacional brasileira e da formação docente, que nos seus diversos espaços vem aos poucos tentado se apropriar deste referencial. Deste modo, podemos destacar que essas mudanças na educação em enfermagem têm como propósito superar o modelo tradicional em que os procedimentos técnicos eram privilegiados, e atender à nova proposta de formação, na qual o aluno se torne emancipado de seu processo de ensino, e que possa atender às demandas do cenário profissional da saúde ${ }^{(7-10)}$.

Soma-se a esse contexto a revolução tecnológica e o processo de reorganização do trabalho na saúde com o advento do Sistema Único de Saúde, que demandam uma completa revisão dos princípios filosóficos e políticos dos currículos da educação profissional técnica de nível médio ${ }^{(11)}$.

Com base neste cenário e com esses pressupostos, como o professor/enfermeiro do ensino profissional técnico concebe a sua prática pedagógica, a partir das transformações que ocorreram na educação? O presente estudo objetivou identificar as práticas pedagógicas, desenvolvidas por professores da educação profissional de nível médio em enfermagem.

\section{- MÉTODO}

Trata-se de uma pesquisa descritiva de abordagem qualitativa, na qual foram utilizados recursos da estatística descritiva e a interpretação dos relatos e da atribuição de significado aos achados. A pesquisa compõe a última etapa de um estudo maior intitulado "A educação profissional técnica de nível médio em enfermagem na cidade de Ribeirão Preto (SP): desafios e perspectivas", que teve como objetivo geral analisar a formação de auxiliares e técnicos de enfermagem, infraestrutura escolar e práticas educativas.

O projeto está em acordo à Resolução 466/2012(12) e foi aprovado pelo Comitê de Ética em Pesquisa, Protocolo $\mathrm{n}^{\circ} 1473 / 2011$, CAAE: 01433012.8.0000.5393. O anonimato dos professores foi garantido com a codificação em sistema alfa-numérico (P1, P2, P3...).

O cenário da pesquisa foi um município do interior do estado de São Paulo, com mais de 600.000 habitantes, referência na área da saúde. Na época da realização do estudo, a cidade contava com um total de 4 escolas de curso de nível médio em enfermagem ( 3 privadas e 1 pública). Todas eram elegíveis para o estudo e foram consultadas sobre a possibilidade de permitirem a participação de seus professores; duas responderam à solicitação e concordaram em participar, ambas privadas, as 
quais possuem o maior contingente de alunos matriculados nos cursos de formação de técnico em enfermagem, 550 alunos; e duas não participaram porque não retornaram aos contatos realizados por telefone ou por email dos pesquisadores.

Considerando a proposta da pesquisa em retratar as práticas pedagógicas, desenvolvidas por professores em sala de aula, os critérios de inclusão dos participantes foram ser professor, com formação superior em enfermagem, ter vínculo com a instituição de ensino há pelo menos um mês e atuar nas disciplinas profissionalizantes. Foram excluídos aqueles que tem atuação esporádica ou eventual, ou que estão exclusivamente como supervisor de ensino nos estágios. O quadro total de docentes de ambas as escolas é de 35 pessoas entre professores e supervisores de estágio. Destes, 21 atenderam aos critérios de inclusão descritos acima; 15 professores aceitaram participar do estudo. Estavam afastados ou em férias 06 professores. A coleta de dados foi realizada entre outubro e novembro de 2013.

A entrevista semiestruturada em duas partes constou de 28 perguntas. Na primeira, explorou-se os aspectos sociodemográficos com 11 perguntas, e na segunda os aspectos concernentes das Práticas pedagógicas (conhecimento sobre Projeto Pedagógico do Curso, Plano de Aula, Método de Ensino, seleção de conteúdos, estratégias de ensino e recursos didáticos, fontes de pesquisa para preparo da aula, uso de material instrucional e avaliação da aprendizagem), com 18 perguntas em que os pesquisados poderiam justificar suas escolhas e ficar à vontade para falar sobre o tema. A análise das respostas compreendeu três fases: na pré-análise, os dados foram organizados e classificados; na sequência, realizou-se a exploração do material e procedeu-se a estruturação dos dados relevantes, categorizando-os e interpretando-os à luz do referencial teórico sobre os elementos da didática ${ }^{(3)}$ constitutivos das práticas pedagógicas, denominadas: "A ausência de sentido e de método no ato de planejar" e "As lacunas do conhecimento didático-pedagógico". Os dados quantitativos foram tratados com cálculo das frequências.

\section{RESULTADOS}

Do total de 15 participantes, 10 (66,6\%) eram do gênero feminino, seis (40\%) tinham entre 30 a 39 anos, oito (53,3\%) tinham especialização em formação docente ou licenciatura, cinco $(33,3 \%)$ cursaram o mestrado e seis (39,9\%) tinham menos de dois anos de experiência assistencial, contudo cinco $(33,3 \%)$ tinham mais de 10 anos.

Sobre as práticas pedagógicas, 53,3\% afirma que realiza o plano de aula, 13,3\% assume que não, e $33,3 \%$ às vezes. Com relação ao programa de disciplina, 53,3\% realiza o planejamento, 20\% não e $26,6 \%$ em parte. Como fonte de pesquisa para o planejamento das disciplinas e das aulas, 53,3\% utilizam sites da internet e $46,6 \%$ livros e apostilas, de forma concomitante ou não. Do total de participantes, $40 \%$ dos professores pesquisados conhecem na íntegra o Projeto Pedagógico do Curso, 46,7\% não e 13,3\% em parte.

A Tabela 1 sintetiza dos dados referentes às opções didático-pedagógicas mais citadas pelos professores pesquisados.

\section{A ausência de sentido e de método no ato de planejar}

Esta categoria identificou nos relatos dos pesquisados uma prática pedagógica individualizada e desconectada do Projeto Pedagógico do Curso (PPC) da escola, ou um processo de adesão ao mesmo, ausente de sentido.

Um dos professores entrevistados, que conhece parcialmente o PPC, explica:

Quando entrei na escola tudo foi muito rápido. Conheço [no PPC] as disciplinas que tenho que preparar e dar aula, e só. (P12)

E um outro, que desconhece o PPC, assim se justifica:

Nunca vi o PPC por falta de tempo. (P9) 
Tabela 1 - Opções didático-pedagógicas dos participantes da pesquisa. Ribeirão Preto, SP, Brasil, 2014

\begin{tabular}{lcc} 
Variáveis & $\mathbf{n}^{\mathbf{0}}$ citações & Frequência \\
\hline Método de ensino que utiliza & & \\
\hline Expositivo & 4 & 26,6 \\
\hline Ativo & 3 & 20 \\
\hline Problematização & 2 & 13,3 \\
\hline Não respondeu & 6 & 40 \\
\hline Como seleciona o conteúdo & & \\
\hline A partir do PPC & 3 & 20 \\
\hline A partir do programa da disciplina & 2 & 13,3 \\
\hline Livros didáticos & 4 & 26,6 \\
\hline De acordo com a realidade do trabalho & 1 & 6,6 \\
\hline Não respondeu & 5 & 33,3 \\
\hline Como realiza a avaliação & & \\
\hline Avaliação formativa & 13 & 86,6 \\
\hline Não respondeu & 2 & 13,3 \\
\hline Instrumentos de avaliação preferido & & \\
\hline Prova escrita & 11 & 73,3 \\
\hline Não respondeu & 4 & 26,7
\end{tabular}

Entretanto, um dos pesquisados demonstrou sua preocupação real em conhecer e desenvolver as práticas pedagógicas alinhadas ao PPC da escola. Reconhece que está distanciado de sua realidade, e que carece de um espaço dialógico. Este entrevistado realizou estágio de graduação do curso de licenciatura na escola em que trabalha atualmente como professor e diz que:

Conheço o PPC porque já foi disponibilizado por inteiro pela coordenação quando eu era aluna, e não como professora. Hoje quase não temos acesso a ele. Pouco se fala e discute sobre o Projeto Pedagógico, mas entendo e aprendi que tudo deve ser baseado no nele: perfil de aluno a ser formado, objetivo e estrutura curricular. (P4)

Sobre o programa da disciplina, identificou-se nos relatos, uma prática individualizada em que o PPC é desconsiderado pelos participantes, como no trecho a seguir, que ilustra este fato:

Sempre faço os programas das disciplinas porque gosto de organização, e o que tem na escola está precisando ser atualizado. Tem assunto importante que a gente não pode deixar de passar. (P6)

Observou-se também a preocupação dos pesquisados em reproduzir o que foi instituído pela escola, como exemplificado a seguir:

Sigo o que a coordenação me passa, procuro não inventar, senão a gente se complica. Tem muito conteúdo. (P1)

A falta de tempo foi o motivo apontado por unanimidade, por aqueles pesquisados que não realizam o plano de aula ou o realizam às vezes. Entretanto, um dos pesquisados evidencia a sua importância no cotidiano, como no trecho a seguir:

O plano de aula é tudo no dia a dia. Fica tudo desorganizado, perdido sem ele. O plano deixa a gente menos estressada e o aluno também. O aluno gosta de organização, mesmo aqueles que parece que não liga, acaba se convencendo. (P6)

\section{As lacunas do conhecimento didático-pedagógico}

Esta categoria identificou as lacunas do conhecimento didático-pedagógico do professor pesquisado, ou seja, uma fragilidade de fundamentos científicos das ações educativas para a formação do técnico de enfermagem. 
Observou-se nos relatos dos pesquisados que os conteúdos são selecionados de forma diversificada, difusa e individualizada, sem considerar os objetivos de aprendizagem:

[...] a partir do que é pedido no programa da disciplina. Seleciono também os conteúdos que eu considero importante, mesmo que não esteja no programa. (P2)

\section{[...] com apoio de material de curso técnico de outra escola. (P4)}

Sobre o método de ensino, os pesquisados que optaram pelo método expositivo, justificaram a sua escolha pela falta de recursos ou pela falta de tempo. Os trechos a seguir ilustram esta questão:

Tentei usar outros métodos, mas no expositivo eu controlo melhor o tempo e o programa. O conteúdo é extenso e a carga horária é curta. (P1)

[...] deve ser considerada a realidade sociocultural do aluno; uso a prática tradicional e tecnicista [...].(P7)

Aqueles que utilizam os métodos participativos e a problematização argumentaram que:

Busco utilizar a metodologia participativa para construir um aprendizado significativo [...] problematizador. (P13)

O aluno deve buscar seu conhecimento e ter autonomia, por isso utilizo do método ativo. Ele cria novas possibilidades para o aluno e ele sai do seu casulo.(P3)

E ainda neste quesito, parte dos pesquisados não identificaram o método que utilizam ou o caracterizaram como estratégias de ensino, como no exemplo a seguir:

\section{[...] conceitual, práticas, simulação de situações e comportamental e através de exemplos. (P9)}

No que concerne ao processo de avaliação da aprendizagem, a opção pela avaliação do tipo formativa foi justificada por um dos pesquisados pela necessidade de evoluir sobre os conhecimentos atitudinais dos alunos, como expresso na fala a seguir:

[...] a avaliação formativa valoriza o conhecimento atitudinal, que precisa ser observado no decorrer da disciplina e em conjunto com a avaliação cognitiva[...]. (P8)

\section{DISCUSSÃO}

O perfil dos professores desta pesquisa é semelhante ao encontrado em outros estudos, ao apontar a presença de $42,8 \%$ (seis de 14) professores do sexo feminino e idade superior a 30 anos $^{(13)} \mathrm{em}$ atividade docente na formação de nível médio em enfermagem. Chamou atenção também a especialização na área pedagógica, a presença de enfermeiros licenciados e também a inserção de mestres nestes espaços.

A exigência legal de formação didático-pedagógico para o enfermeiro atuar na formação de auxiliares e técnicos de enfermagem, surge em 1968 Parecer no $837 / 68^{(14)}$ na tentativa de preparar um profissional competente com vivência docente desde o início de sua formação. No ano de 2001, as DCNs do Curso

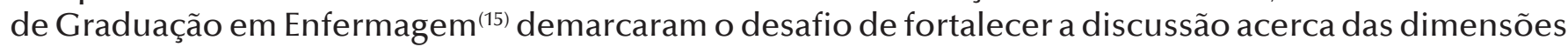
pedagógicas contempladas no curso de Bacharelado e a reestruturação da Licenciatura. Entretanto, a ausência de Cursos de Licenciatura e a demanda elevada por professores/enfermeiros propiciou aumento da Pós-Graduação lato sensu, ou Cursos de Especialização em Formação Docente ${ }^{(16)}$. No que se refere ao mestrado para formação de professores, discute-se que os programas de pós-graduação muitas vezes se voltam para formação de pesquisadores ${ }^{(17)}$.

Apesar de todo o esforço das leis para a formação de professores-enfermeiros, sabe-se que a seleção de professores para este nível de ensino, muitas vezes ainda é feita pela eloquência do profissional e sua comprovada experiência na área da enfermagem ${ }^{(16,18)}$. Contudo, as habilidades pedagógicas são necessárias na construção da prática do professor articulada coerentemente ao PPC, para que atinja os objetivos da aprendizagem ${ }^{(17)}$.

Sobre a presença de professores com menos de dois anos de experiência profissional, estudo 
de revisão identificou que ao findar a graduação, muitos enfermeiros se tornam professores sem conhecimento específico e aprofundado dos aspectos do cuidado em saúde, e das práticas didáticas e pedagógicas(19). Refletir sobre suas práticas, significa reorganizar o pensamento a partir da experiência vivenciada, num processo sistematizado de análise, que possa evitar as armadilhas da reprodução de ideias pré-existentes e superficiais ${ }^{(20)}$. Pressupõe-se que para qualificar o trabalho, o professor reflita, pesquise e se comprometa com sua atualização permanente, disposto ao trabalho coletivo e à ação crítica e cooperativa ${ }^{(2,4-5,9,17,19)}$.

Apesar de não ter sido realizado no âmbito do conhecimento específico da enfermagem, estudo realizado em escolas públicas apontou a necessidade das Horas de Trabalho Pedagógico Coletivo, compreendidas como espaços de diálogo, reflexão e articulação de conhecimentos, saberes e práticas dos professores e gestores ${ }^{(21)}$.

De acordo com as DCNs para a Educação Profissional Técnica de Nível Médio, o PPC deve ser construído coletivamente e democraticamente, tanto pelos profissionais que atuam na escola, gestores, funcionários e professores, como pela comunidade de uma maneira geral. O professor ainda tem papel secundário nesta construção, e seus saberes não são devidamente valorizados. Aprofundar as discussões sobre estas matizes, traz lucidez e compromisso daqueles que delas participam, num processo continuado e coletivo de aprendizagem da prática docente ${ }^{(2,6-7)}$.

Estudo sobre a percepção da prática docente no ensino técnico em Enfermagem, concluiu que a troca de ideias sobre a matriz curricular é um recurso pouco utilizado pelos professores para a avaliação da sua prática pedagógica, justificada pela falta de oportunidade ou por não exigência da escola. Comprovou-se que os professores não possuem o hábito de discutir as vivências da didática usada em sala de aula ${ }^{(5)}$. A falta de reuniões pedagógicas foi relatada, o que pode justificar o trabalho individualizado do professor e a ausência de um proposta coletiva para a formação de um trabalhador crítico e reflexivo, competente e ético.

Por conseguinte, nossa pesquisa aponta que mais da metade dos entrevistados realiza planejamento das aulas, e utiliza a internet enquanto um recurso tecnológico para a busca de informação além de livros e apostilas, enquanto os demais assumem que não o realiza ou realiza em parte. O plano de aula é responsável pela articulação do PPC, e o valoriza quando vislumbra a formação integral do aluno ${ }^{(2,22-23)}$. Trata-se de um instrumento do trabalho docente que irá ajudá-lo a direcionar e organizar suas ações, a fim de atingir os objetivos propostos de aprendizagem. Este registro implica numa reflexão permanente do professor sobre o processo que se responsabiliza no seu cotidiano ${ }^{(3,23)}$. O professor que desenvolve a aula com um plano que está apenas em mente, não registrado, atua de forma assistemática. Limita-se a cumprir uma atividade estanque, por vezes descontextualizada e atemporal, e que possivelmente irá obscurecer o objetivo da aprendizagem e o processo de avaliação ${ }^{(19,23)}$.

Com relação ao método de ensino que utilizam, as respostas oscilaram entre método tradicional e o ativo. Importante ressaltar que $40 \%$ dos pesquisados não respondeu à questão ou quando o fez confundiu método com estratégia de ensino. Método de ensino é o caminho definido pelo professor para promover e facilitar a aprendizagem do aluno ${ }^{(23-24)}$.

Todo método traz implícito um referencial teórico, concepções que orientam o trabalho docente ${ }^{(3)}$. As metodologias ativas que são fundamentadas na concepção pedagógica crítico-reflexiva, partem de contextos de vida real, intervindo sobre a realidade, de forma a estimular a interação entre os diversos atores. Incentiva-se a valorização da construção coletiva do conhecimento em seus diferentes saberes e cenários de aprendizagem. Como consequência, estimulam a criatividade na construção de soluções aos problemas, e promovem a liberdade de pensar e agir. A problematização tem sido muito utilizada como estratégia de ensino, aprendizagem e avaliação na metodologia ativa, por se ancorar na concepção pedagógica que estimula a participação do educando, desenvolvendo a autonomia e a compreensão da responsabilidade individual e coletiva no processo de aprendizagem ${ }^{(25-26)}$. Um dos professores menciona a palavra sair do casulo, que em nosso entendimento significa a possibilidade que o método ativo oferece na construção da identidade profissional com autonomia.

No que se refere à seleção do conteúdo a ser ministrado, 40\% dos professores pesquisados utiliza o programa da disciplina ou o PPC. Conteúdos são bases para a manifestação prática em que se articulam conhecimentos (abstração de uma ideia e sua incorporação mental), habilidades 
(destreza para a realização de uma atividade) e atitudes (posição assumida frente a uma questão), e estão ligados à própria existência da escola e sua função social(22). Na Educação de Nível Médio em Enfermagem, a seleção de conteúdo de aprendizagem volta-se para a construção de competências. Esta é compreendida como uma combinação de conteúdos que mobilizados geram uma ação eficaz do profissional num determinado contexto particular (23). "Ser competente é saber fazer bem o dever" (24:19). Ao dever se articula o domínio cognitivo, procedimental e atitudinal do profissional em contextos específicos do cuidado em saúde ${ }^{(25-26)}$.

Legalmente, as competências mínimas para a formação profissional estão expressas nas Diretrizes Curriculares Nacionais (DCNs) e pelos Referenciais Curriculares Nacionais (RCNs). Estes documentos guiam a elaboração do planejamento de ensino, com a identificação de funções e subfunções, distinguindo competências, habilidades e bases tecnológicas nelas envolvidas ou para elas necessárias ${ }^{(7,27-28)}$, ou seja, a combinação de conteúdos necessários para formação básica do técnico de enfermagem.

Muitos professores referiram-se à avaliação formativa, contudo fazem opção pela prova escrita, pois para medir o conhecimento ainda é a prática mais valorizada nesse nível de ensino, confirmando a tendência histórica em enfermagem, no qual os conteúdos procedimentais e factuais são mais valorizados e avaliados ${ }^{(29)}$. O que diverge do conceito de avaliação formativa, pois esta acontece durante o processo, objetivando refletir sobre os caminhos tomados, principalmente na escolha do método de ensino. Difere-se da avaliação classificatória ou somativa, aquela que quantifica o conhecimento acumulado pelo aluno ${ }^{(30)}$.

\section{- CONCLUSÃO}

Este estudo permitiu perceber que os professores estão preocupados com o comprometimento do seu trabalho. Entretanto, em linhas gerais, desenvolvem uma prática educativa desprovida de reflexão e sentido ao atribuir valor relativo ao planejamento do curso. Por outro lado, constatou-se que a maioria dos professores realiza o planejamento da disciplina e da aula, porém sem uma articulação clara entre o método de ensino, a seleção de conteúdo e a avaliação da formação.

Se por um lado, encontramos professores com avanços em suas falas, que denotam linguagem progressista sobre a sua prática pedagógica, por outro as respostas estão permeadas de contradição e falta de coerência sobre os aspectos que embasam a educação aos princípios das DCNs.

A ausência das DCNs nos relatos pode representar distanciamento dos participantes com o cerne das questões que sustentam a proposta de mudança na formação do técnico de enfermagem, e que explica em parte a falta de sentido e as lacunas encontradas nas respostas emitidas. Por isso, constatouse que a apropriação do PPC não implica em um compromisso construído coletivamente. Neste sentido, os participantes não estão envolvidos numa discussão crítica e reflexiva sobre a formação do técnico.

E ainda, foi percebida nesta pesquisa uma desarticulação do conhecimento pedagógico com a prática realizada em sala de aula pela maioria dos professores pesquisados. Há ausência de opção pelo método de ensino e a forma de selecionar o conteúdo, ou uma compreensão equivocada sobre o seu significado, bem como da avaliação formativa, pois esta foi relacionada ao conhecimento atitudinal que o aluno deve construir. Em contrapartida a prova escrita foi o instrumento preferido dos pesquisados.

Nossa pesquisa mostra uma transição entre o processo avaliativo aos moldes de uma modelo tradicional de ensino, reflexo de um currículo fragmentado por disciplinas, em que prevalece o processo avaliativo no âmbito cognitivo, contribuindo para a avaliação somativa e prejudicando a formativa.

Persiste também, por parte dos professores, a escolha pelo método de ensino tradicional, sendo a falta de tempo a justificativa da maioria para esta opção, desconsiderando os princípios postos pelas DCNs.

Consideramos finalmente neste estudo, a presença de fragilidade significativa na formação didáticopedagógica dos pesquisados, a ser superada pelo aprofundamento conceitual das dimensões que 
compõem a prática pedagógica, para que se alinhem de forma consciente às Diretrizes Curriculares Nacionais na formação do técnico de enfermagem.

Nesta perspectiva, este estudo levantou a necessidade de fortalecer a gestão escolar, que no seu planejamento precisa favorecer e valorizar as reuniões que possam propiciar discussões críticas e reflexivas sobre o mesmo, num processo de familiarização que o torne parte indissociável do cotidiano escolar, ou seja, da prática pedagógica e da educação permanente dos professores. Para isso, é preciso avançar na elaboração de plano de aula com a utilização de método de ensino que construa uma formação do técnico crítico e reflexivo.

Considera-se finalmente, a também necessidade da cumplicidade dos professores com a construção e o desenvolvimento do PPC da escola, pois este traz a essência do trabalho coletivo para a formação de profissionais/cidadãos em função de uma sociedade que fez e faz escolhas políticas para a saúde continuamente.

\section{REFERÊNCIAS}

1. Gubert E, Prado ML. Desafios na prática pedagógica na educação profissional em enfermagem. Rev. Eletr. Enf. 2011; 13(2):285-95.

2. Cruz GB. A prática docente no contexto da sala de aula frente às reformas curriculares. Educ. rev. 2007; (29):191205.

3. Malheiros BT. Didática geral. Rio de Janeiro: LTC; 2013.

4. Felício HMS, Possani LFP. Análise crítica de currículo: um olhar sobre a prática pedagógica. Currículo sem Fronteiras. 2013; 13(1):129-42.

5. Cordeiro VJ. Prática pedagógica no processo ensino-aprendizagem: um estudo de caso na escola profissionalizante Senac/Concórdia, SC. B. Téc. Senac: a R. Educ. Prof. 2010; 36(3):65-71.

6. Costa GMT. Projeto político-pedagógico: elementos de sua identidade e situações pedagógicas do cotidiano que são provocadoras de um processo de ressignificação. Rev.de Ed. do IDEAU. 2011; 6(14):1-17.

7. Ministério da Educação (BR). Resolução n. 6, de 20 de setembro de 2012. Define Diretrizes Curriculares Nacionais para a Educação Profissional Técnica de Nível Médio. DiárioOficial da União. Brasília; 2012.

8. Allen S. The revolution of nursing pedagogy: a transformational process. Teaching and Learning in Nursing. 2010; 5(1):33-8.

9. Frenk J, Chen L, Bhutta ZA, Cohen J, Crisp N, Evans T, et al. Health professionals for a new century: transforming education to strengthen health system in an interdependent world. The Lancet. 2010; 376(9756):1923-58.

10. Mata LRF, Madeira AMF. Análise da produção científica sobre educação profissionalizante da enfermagem brasileira: uma revisão integrativa. Reme, Rev. Min. Enferm. 2010; 14(3):424-33.

11. Bonfada D, Cavalcante JRLP, Araujo DP, Guimarães J. A integralidade da atenção à saúde como eixo da organização tecnológica nos serviços. Ciênc. saúde coletiva. 2012; 17(2):555-60.

12. Ministério da Saúde (BR). Conselho Nacional de Saúde. Diretrizes e normas regulamentadoras de pesquisa envolvendo seres humanos. Resolução n. 466, de 12 de dezembro de 2012. Brasília; 2012.

13. Frazoni RC, Mello e Souza MCB. Educação profissional técnica de nível médio em enfermagem: perfil sócio econômico dos professores de um município do estado de São Paulo. G\&S. 2013; (n.esp):1958-71.

14. Ministério da Educação (BR). Câmara de Ensino Superior. Parecer n. 837/68. Criação do Curso de Licenciatura em Enfermagem. Brasília: Ministério da Educação; 1968.

15. Ministério da Educação (BR). Conselho Nacional de Educação. Resolução n. 3, de 07 de novembro de 2001. Institui Diretrizes Curriculares Nacionais do Curso de Graduação em Enfermagem. Diário Oficial da União. 
Brasília; 2001.

16. Santos LMC, Ribeiro KRB, Oliveira JSA, Padilha MICS, Borenstein MS. A Licenciatura em Enfermagem no Brasil (1968-2001): uma revisão da literatura.Hist. Enf. Rev. Eletr (HERE). 2014; 5(2):224-38.

17. Püschel VAA. Ser professor de enfermagem. CogitareEnferm. 2012; 17(1):9-14.

18. Lima EC, Appolinário RS. A educação profissionalizante em enfermagem no Brasil: desafios e perspectivas. Rev.enferm UERJ. 2011; 19(2):311-6.

19. Maissiat GS, Carreno I. Enfermeiros docentes do ensino técnico em enfermagem: uma revisão integrativa. Rev. Destaques acadêmicos. 2010; 2(3):69-80.

20. Nóvoa A. Para una formación de profesores construida dentro de laprofesión. Revista de Educación. 2009; (350):203-18.

21. Cunha RCOB, Ometto CBCN, Prado GVT. Trabalho docente coletivo e coordenação pedagógica: entre a heterogeneidade do cotidiano e um projeto de formação de professores. Rev. educ. PUC-Camp. 2013; 18(2):1719.

22. Castro PAPP, Tucunduva CC, Arns EM. A importância do planejamento das aulas para organização do trabalho do professor em sua prática docente. ATHENA. Revista Científica de Educação. 2008; 10(10):49-62.

23. Libâneo JC. Didática. São Paulo: Cortez; 2008.

24. Rios TA. Ética e competência. São Paulo: Cortez; 2011.

25. Silva LS, Cotta RMM, Costa GD, Campos AAO, Cotta RM, Silva LS, et al. Formação de profissionais críticosreflexivos: o potencial das metodologias ativas de ensino-aprendizagem e avaliação na aprendizagem significativa. Revista CIDUI. [Internet] 2014; (2) [acesso em 15 mai 2015]. Disponível:http://www.cidui.org/revistacidui/index. php/cidui/article/view/541.

26. Christofoletti G, Fernandes JM, Martins AS, Oliveira Junior SA, Carregaro RL, Toleto AM. Grau de satisfação discente frente à utilização de métodos ativos de aprendizagem em uma disciplina de Ética em saúde. Revista Eletrônica de Educação. 2014; 8(2):188-97.

27. Cordão FA. As novas diretrizes curriculares nacionais para a educação básica e suas implicações na educação profissional técnica de nível médio. B. Téc. Senac: a R. Educ. Prof. 2011; 37(3):41-55.

28. Marcon D, Graça ABS, Nascimento JV. Busca de paralelismo entre conhecimento pedagógico do conteúdo e processo de raciocínio e ação pedagógica. Educ. rev. 2011; 27(1):261-94.

29. Oliveira JM, Maftum MA, Wall ML. Critérios de avaliação de alunos: uma construção dos docentes do curso técnico em enfermagem do CEPE. CogitareEnferm. 2005; 10(1):26-33.

30. Black P, Wiliam D. Developing the theory of formative assessment. Educ.Asse.Eval. Acc. 2009; 21(1):5-31. 